\title{
Wear Characteristics in Al-SiC Particulate Composites and the Al-Si Piston Alloy
}

\author{
Z. Hasan ${ }^{1}$, R. K. Pandey ${ }^{2}$, D.K. Sehgal ${ }^{2} *$ \\ ${ }^{1}$ Mech. Engg. Dept., JIET, Jahangirabad, Barabanki, Utter Pradesh,225203, India \\ ${ }^{2}$ Applied Mech. Dept., IIT Delhi, Hauz Khas, New Delhi, India. \\ * Corresponding Author : zahir_hasan@yahoo.com,rkpiitd@yahoo.com, \\ profsehgal@yahoo.om
}

\begin{abstract}
:
The Al-Si alloy with near eutectic composition has been conventionally used as a piston material for automobile applications. It is required to possess high abrasive wear resistance for enhanced life of the engine. The alloy is known to have fairly good wear resistance due to increased percentage of silicon present in fine form. In the present investigation, Al-SiC particulate composites have been studied for their wear resistance against emery paper (400 grit SiC particles) counterface and a comparison has been made with existing piston alloy i.e. Al-Si alloy.

The Al-SiC composites have been prepared using Liquid Metallurgy technique employing 2124 Alalloy as the base material with 10 and $20 \%$ SiC particulates by weight. The abrasive wear study has been conducted on a Pin on Disc machine. The wear rate in terms of weight loss per unit sliding distance as well as the volumetric wear rate have been obtained for the Al-SiC composites. The characteristics of worn surface were investigated using SEM. The composites are found to possess very high wear resistance as compared to Al-Si piston alloy. The results have been discussed and important conclusions are outlined.
\end{abstract}

Key words: Composite Material, Wear, SEM.

\section{INTRODUCTION}

There are more than 50,000 materials available for engineers to the design and manufacturing of products for various applications. These materials range from ordinary materials (e.g., copper, cast iron, brass), which have been available for several hundred years, to the advanced materials e.g., composites, ceramics and high-performance steels etc.

The life of automobile depends on its engine having piston and cylinder made from suitable alloys. The Al-based composites have found extensive applications in automobile industries due to their increased stiffness, strength and wear resistance properties. A number of particulate 
phases have been employed in the Al-alloy matrix [1]. For example, particulates of graphite [2], mica [3], zirconia, alumina[4], zircon[5], silicon-carbide[6], silica [7] etc. have been employed in a suitable Al-alloy matrix. The introduction of the above particulate phases in the aluminium matrix provides a good wear resistance and antifriction properties. The strength, ductility and stiffness are the other important properties. The choice of an optimum volume fraction of the particulate phase in the composite is therefore essential to obtain an improved combination of properties.

The present investigation is based on the study of Al-SiC cast composites with particular reference to the study of the effect of particulate phase on the wear characteristics of the composites.

\section{MATERIALS AND METHODS}

\subsection{Composite Preparation}

For the present investigation four types of materials have been selected as follows

(i) Al-alloy (2124 type)

(ii) $\quad$ Al-alloy $-10 \% \mathrm{SiC}(\mathrm{wt} \%)$ composite

(iii) Al-alloy $-20 \% \mathrm{SiC}(\mathrm{wt} \%)$ composite

(iv) Al-Si piston alloy

The composites as well as Al alloy (2124 type) plates were obtained from the Regional Research Laboratory (RRL) Thiruvananthapuram (India). The 2124 Al-alloy has been used as the base alloy for the composite. The composition of the above alloy is given in Table 1. The composites were prepared using liquid metallurgy technique. During the preparation of composite, addition of $0.5 \mathrm{wt} \% \mathrm{Mg}, 0.005 \mathrm{wt} \% \mathrm{Be}$ and $0.07 \mathrm{wt} \% \mathrm{TiB}$ were made along with the SiC particulates. The $\mathrm{SiC}$ particles were lying in the size range of $23-40 \mu \mathrm{m}$. The $\mathrm{TiB}$ is used for the grain refinement whereas Be is added for improved castability. For the improvement of interfacial bonding of $\mathrm{SiC}$ particles, the surface of the latter is oxidized. This is performed by preheating of the $\mathrm{SiC}$ particles in the temperature range of $700-900{ }^{\circ} \mathrm{C}$. Proper stirring and mixing of particles are done to ensure uniform distribution of $\mathrm{SiC}$ particles. The addition of $\mathrm{Be}$ is also known to improve the distribution of $\mathrm{SiC}$ particles by minimizing the agglomerations of particles.

The plates were cast using split moulds and employing bottom pouring technique. After casting the composite plates were obtained in the dimensions of $250 \mathrm{~mm}$ (length) x $225 \mathrm{~mm}$ (width) $\mathrm{x} 40$ mm (thickness).

\subsection{Processing of Composites}

The cast plates of the base alloy as well as the composites were soaked in a furnace for 2 to 3 hrs in the temperature range of $480-500{ }^{\circ} \mathrm{C}$. The plates were forged in the above temperature range using hydraulic press of 3000 Ton capacity. The final reduction after forging resulted in the plate thickness of 15-17 $\mathrm{mm}$ from the original $40 \mathrm{~mm}$ thickness. 


\subsection{Aluminium -Silicon Alloy}

In the present investigation an Al-Si eutectic alloy has been employed for comparison of its wear behaviour with the wear behaviour of Al-SiC composites. The composition of the alloy is given in Table 1. The alloy was phosphorous (P) modified by using 70-80 ppm of P. The piston had been made by gravity die casting followed by artificial aging heat treatment. The heat treatment involved solution treatment at $505{ }^{\circ} \mathrm{C}$ for $2 \frac{1 / 2}{2}$ hours, then water quenching at $65^{\circ} \mathrm{C}$ and subsequently aging at $205{ }^{\circ} \mathrm{C}$ for 5 hours. The above heat treatment was known to result in optimum properties. After the above heat treatment following properties were obtained: Proof stress- 205-225 MPa, Tensile Strength - $300 \mathrm{MPa}$, \%Elongation - 0.3 to $1.5 \%$, Hardness - 65 HRB.

TABLE 1. Chemical Composition of the Base Al-Alloy

\begin{tabular}{|l|c|c|c|c|c|c|c|c|c|c|c|}
\hline Element & $\mathrm{Cu}$ & $\mathrm{Zn}$ & $\mathrm{Mn}$ & $\mathrm{Fe}$ & $\mathrm{Mg}$ & $\mathrm{Si}$ & $\mathrm{Ti}$ & $\mathrm{Sn}$ & $\mathrm{Pb}$ & $\mathrm{Ni}$ & $\mathrm{Al}$ \\
\hline $\begin{array}{l}\text { Base Al- } \\
\text { alloy (Wt } \\
\text { \%) }\end{array}$ & 5.10 & 1.13 & 0.592 & 0.565 & 0.454 & 4.09 & 0.112 & 0.015 & 0.044 & - & $\mathrm{Rest}$ \\
\hline $\begin{array}{l}\text { Al-Si piston } \\
\text { alloy (Wt } \\
\text { \%) }\end{array}$ & 1.1 & - & 0.2 & 0.3 & 1.1 & 12.5 & - & - & - & 0.9 & Rest \\
\hline
\end{tabular}

\section{WEAR EXPERIMENTATION}

The wear studies were conducted using a pin on disc machine (Linear Abrasive Wear Rig) [8]. The maximum loading capacity was $200 \mathrm{~N}$ and maximum speed of $5 \mathrm{~m} /$ minute. The specimens for wear studies were cut from the base Al- alloy, composite plates and the Al-Si piston alloy in cross section of $10 \mathrm{~mm} \times 10 \mathrm{~mm}$ with a thickness of $8 \mathrm{~mm}$. The top and bottom surfaces were made planer by polishing against emery paper. The specimen was fixed on the specimen holder which in turn was mounted to the machine. The disc was provided with 400 grit emery paper to be used as the counter facing surface. For the wear test, the total travel distance covered was 100 $\mathrm{m}$ which was divided into 5 equal parts. The movement of specimen on the disc was continued along the same path for the distance of $20 \mathrm{~mm}$ in reciprocating manner. The dry sliding wear test was conducted in this study. After the coverage of each $20 \mathrm{~m}$ distance, the path was changed and a fresh path was used. The distance of $20 \mathrm{~m}$ was covered by 40 cycles of travel in a reciprocating manner as because the travel step was of $250 \mathrm{~mm}$ length. A travel speed of $3 \mathrm{~m} / \mathrm{min}$ was used during the test.

The specimen was weighed initially using an electronic balance of $0.0001 \mathrm{gm}$ accuracy and the maximum capacity of $320 \mathrm{gm}$. After a travel distance of $20 \mathrm{~mm}$ on the disc, the sample was taken out, cleaned and weighed carefully. This was continued for entire travel distance of $100 \mathrm{~m}$. The wear studies were conducted at 3 different load levels i.e. $20 \mathrm{~N}, 30 \mathrm{~N}$ and $50 \mathrm{~N}$.

\subsection{Wear Surface Study}

The samples for wear surface study were sectioned carefully to appropriate sizes. They were cleaned using ultrasonic cleaner and examined under SEM (Zeiss EVO-50) at suitable 
magnifications. The wear surface of each specimen was examined after completing its final applied load.

\section{RESULTS}

\subsection{Effect of Load and Disc Surface on Weight Loss}

The effect of load employed during wear test is presented in Fig. 1 on various materials i.e. Al base alloy, $10 \% \mathrm{SiC}$ Composite, $20 \% \mathrm{SiC}$ composite and Al-Si piston alloy. In the above figure the weight loss from the four materials is presented for loads $20 \mathrm{~N}, 30 \mathrm{~N}$ and $50 \mathrm{~N}$ in Figs. 1(a), $1(b)$ and 1(c) respectively for 400 grit emery paper used as the disc surface.

Following observations may be made from Fig. 1:

(a) With increasing load the weight loss increases in all the four materials.

(b) With increasing travel distance the weight loss increases in all the materials at a given load.

(c) For a given load and distance travelled the, weight loss is found to be maximum in the Al-Si piston alloy and minimum in the Al- 20\% SiC composite. The Al-base alloy shows greater weight loss as compared to both the composites for a given load and travel distance.
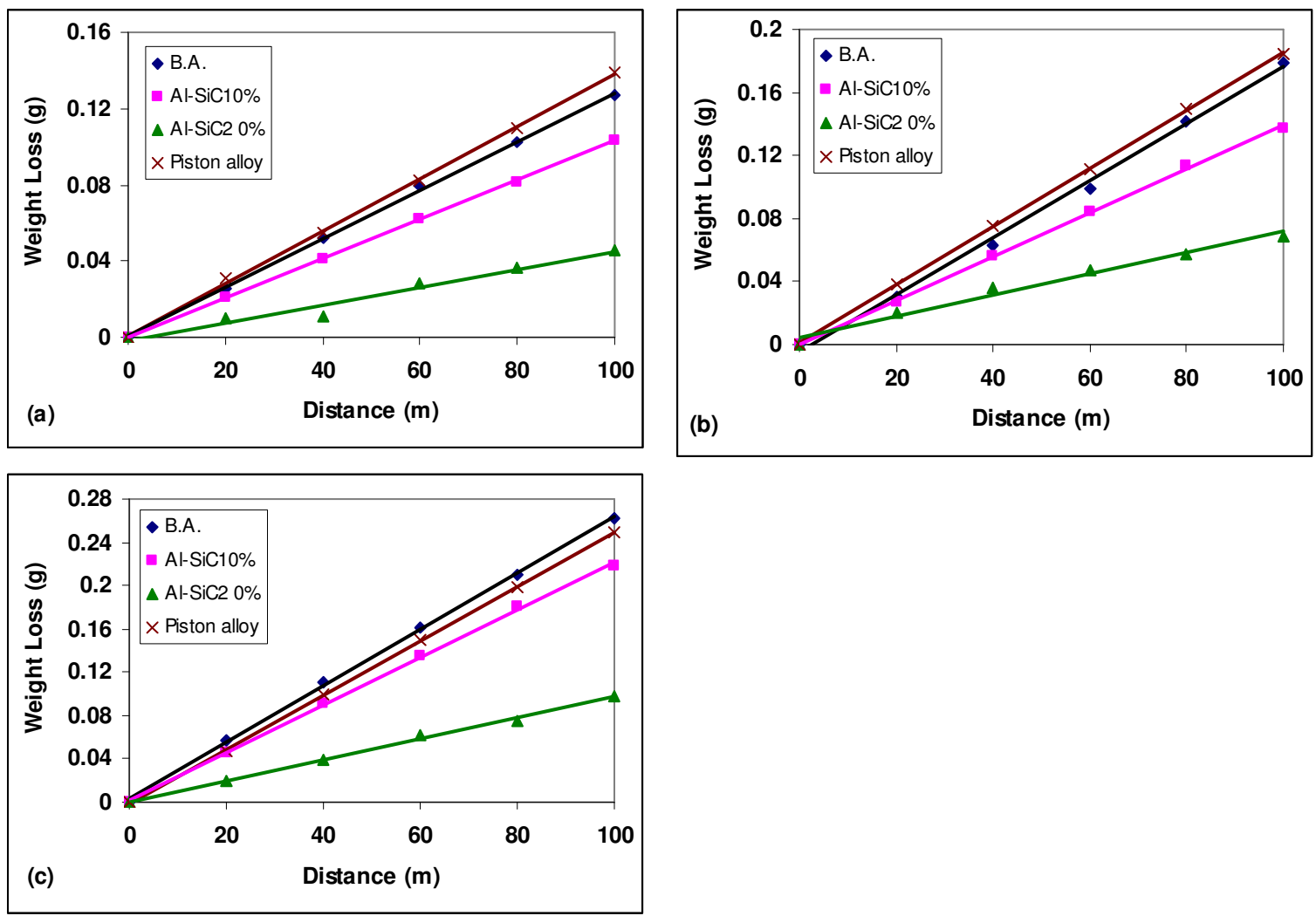

Fig.1 Weight loss as a function of sliding distance for 400 emery paper
(a) $20 \mathrm{~N}$
(b) $30 \mathrm{~N}$
(c) $50 \mathrm{~N}$ 

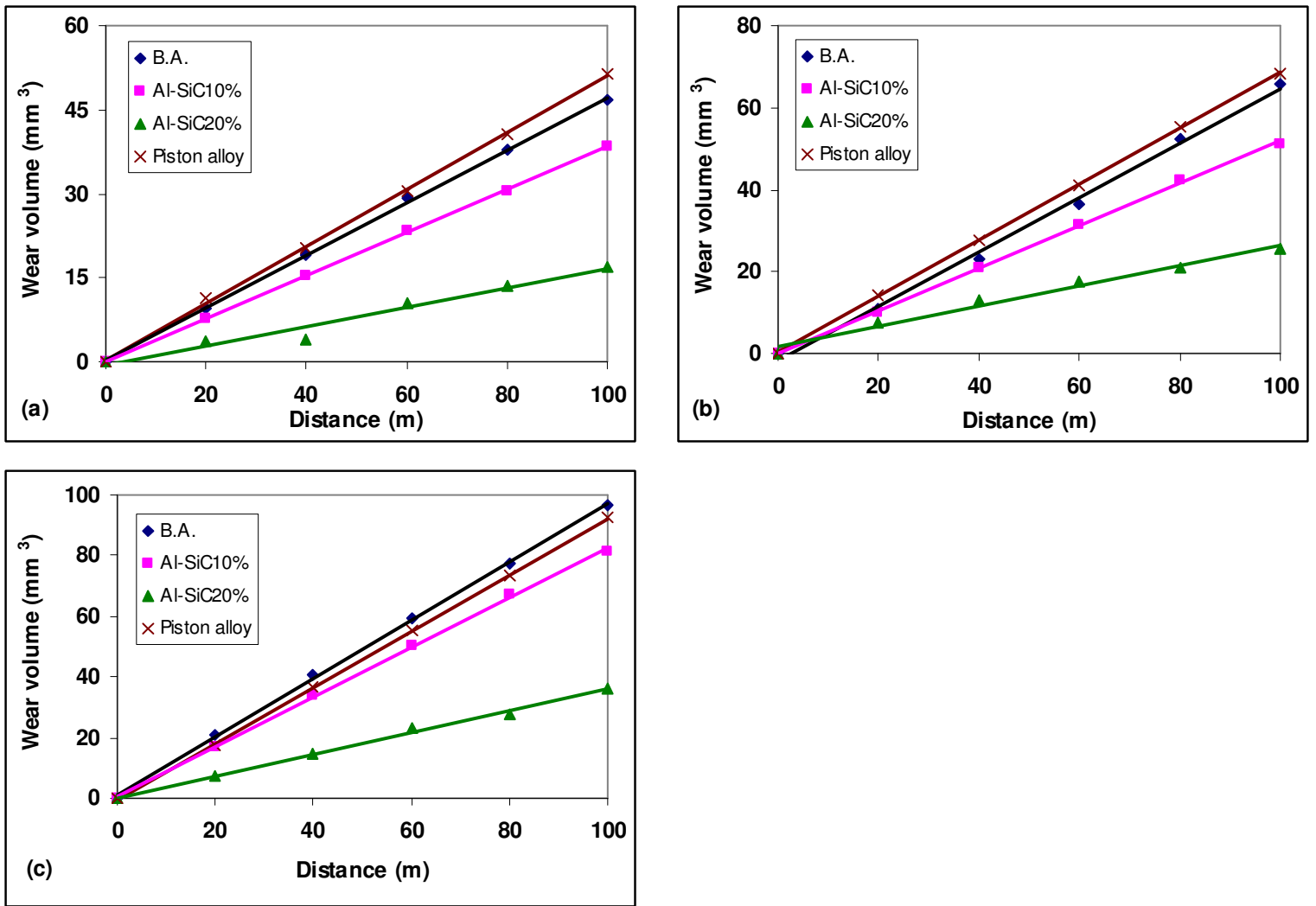

Fig. 2 Wear volume as a function of sliding distance for 400 emery paper
(a) $20 \mathrm{~N}$
(b) $30 \mathrm{~N}$
(c) $50 \mathrm{~N}$

\subsection{Effect of Load and Disc Surface on the Wear Volume}

The wear volume was calculated as follows.

$$
\text { Wear Volume }=\frac{\text { Cumulative weight loss }}{\text { Density }}
$$

The calculated wear volumes were plotted against the sliding distance for the materials investigated at different loads. Fig. 2 presents the wear volume vs sliding distance diagrams for 400 grit emery paper at $20 \mathrm{~N}, 30 \mathrm{~N}$ and $50 \mathrm{~N}$ of loads.

From the above diagrams following observations may be made.

a) The wear volume in all the situations is the minimum for the Al-20\% $\mathrm{SiC}$ composite.

b) The maximum wear volume is noticed either for the Al-Si piston alloy or the Al-base alloy.

c) The performance of $\mathrm{Al}-10 \% \mathrm{SiC}$ composite almost lies in between the maximum and the minimum wear volume.

d) With increasing load there is consistent increase in the wear volume. 


\section{WEAR SURFACE STUDIES USING SEM}

For the wear study following wear test specimens were selected

(a) $\mathrm{Al}-10 \% \mathrm{SiC}$ composite at $50 \mathrm{~N}$ load

(b) $\mathrm{Al}-20 \% \mathrm{SiC}$ composite at $50 \mathrm{~N}$ load

Representative SEM diagrams from the wear surfaces of Al-10\% SiC composite against 400 emery paper are presented in Fig. 3. The Fig.3 (a) provides overall view of wear pattern at 2000 X. Fig. 3(b) provides an enlarged view of material removal from the surface at $4500 \mathrm{X}$. The wear surface features from Al-20\% SiC composite are shown in Figs 4 (a) and (b). Fig 4(b) provides details of wear track and process of materials removal.
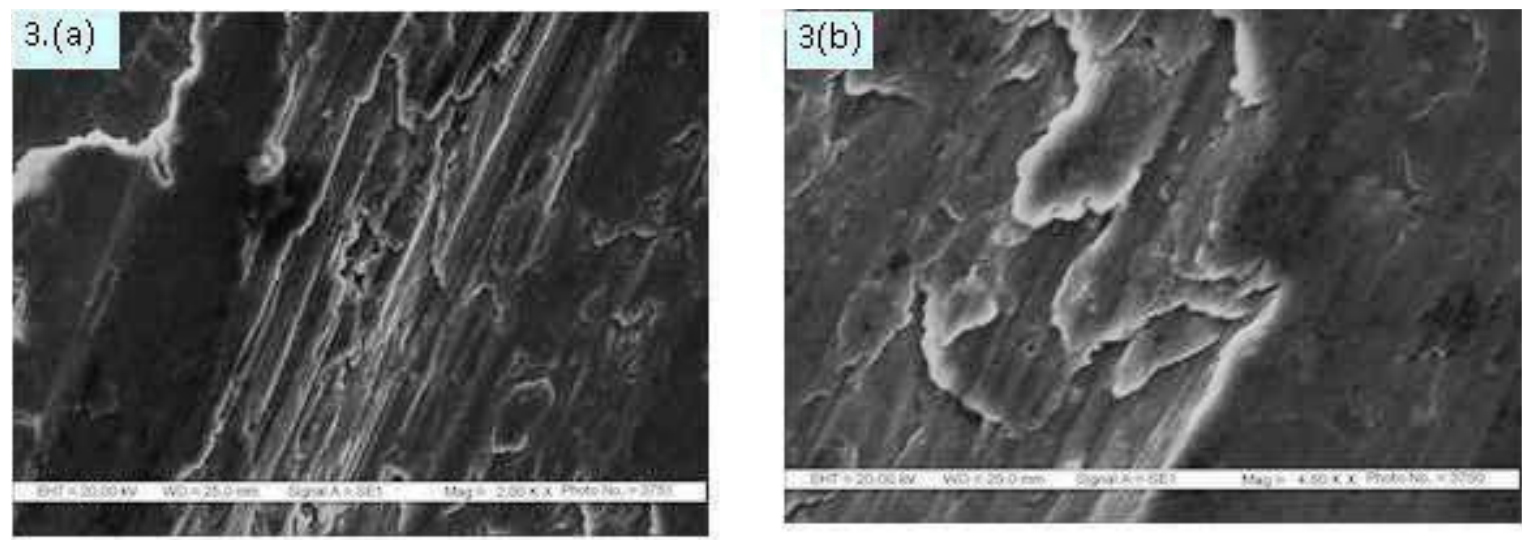

Fig. 3(a-b) Wear surface characteristics (SEM) of $\mathrm{Al}-10 \% \mathrm{SiC}$ Composite ( 400 emery, $\mathrm{P}=50 \mathrm{~N}$ )
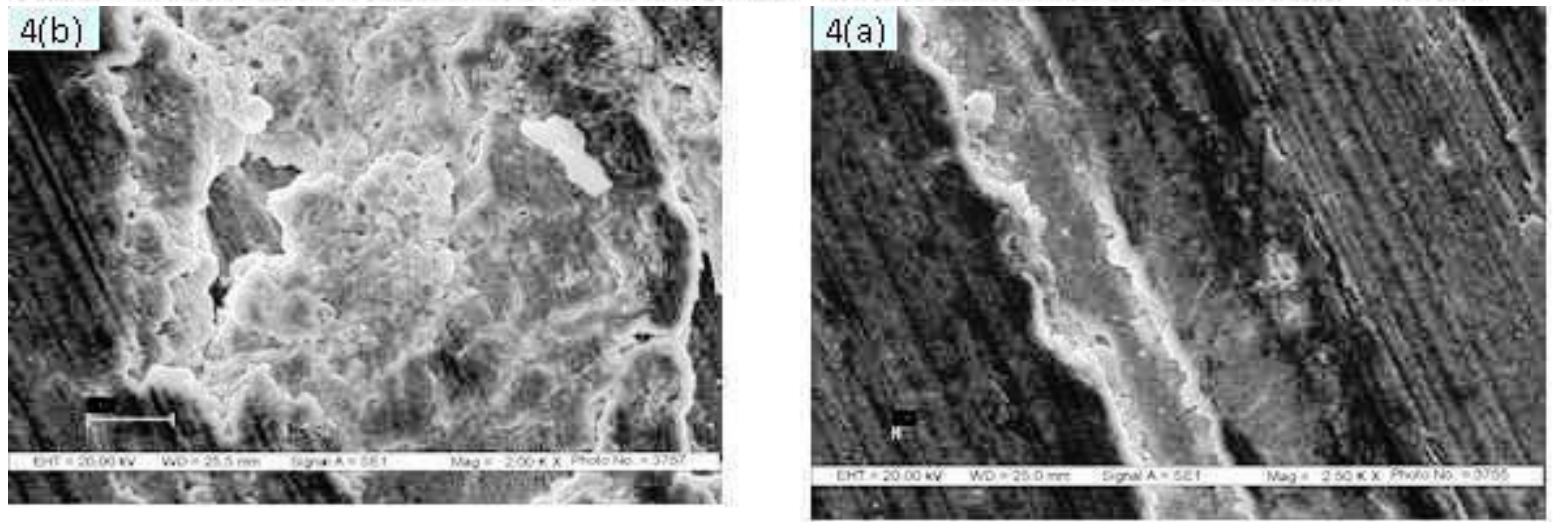

Fig. 4(a-b) Wear surface characteristics (SEM) of $\mathrm{Al}-20 \% \mathrm{SiC}$ Composite ( 400 emery, $\mathrm{P}=50 \mathrm{~N}$ )

\section{DISCUSSION AND CONCLUSIONS}

1. The dry sliding wear behavior in the base alloy and composites were investigated against emery papers of 400 grit. The $\mathrm{SiC}$ particulate phase is found to reduce the wear rate (expressed in terms of $\mathrm{gm} / \mathrm{m}, \mathrm{mm}^{3} / \mathrm{m}$ etc) significantly in the composites. The volumetric wear rate $\left(\mathrm{mm}^{3} / \mathrm{m}\right)$ in $20 \% \mathrm{SiC}$ composite is reduced by $62-66 \%$ for 400 emery sliding with respect to the base alloy. In case of $10 \% \mathrm{SiC}$ composite the corresponding reduction in the wear rate is $15-25 \%$. 
2. The wear rate is found to increase with load in all the materials studied. The increase in wear rate with load is steeper in the base alloy as compared to that of the composites. The increasing load is known to produce heating effect leading to thermal softening and seizure. Also it brings more area into sliding contact and thereby causes enhanced wear.

3. With increasing size of the abrasive particles (in the emery paper) the wear rate of the materials investigated has been increased. The effect of increasing abrasive particle size from $15 \mu \mathrm{m}$ to $38 \mu \mathrm{m}$ has been studied. The increase in wear rate of the base alloy is more significant due to cutting and plowing action by large abrasive particles. In case of composites (especially $20 \% \mathrm{SiC}$ composite) the effect of abrasive particles size on the wear rate is less significant as reported by other investigates also [9]. However at higher load the effect of abrasive particle size on the wear rate of composites is more significant.

4. The micromechanism of wear against the coarse abrasive emery paper was found to be characterized by deep wear tracks along with fragmented $\mathrm{SiC}$ particulates in the $10 \% \mathrm{SiC}$ composite. Fine cracks were also noticed. In $20 \% \mathrm{SiC}$ composite wear was followed by limited extent of cutting and plowing marks keeping the overall surface smooth.

5. The wear rate in the Al-Si piston alloy is found to be significantly higher than that of the composites. The volumetric wear rate in this alloy is closer to the same as in the Al- base alloy [10].

\section{REFERENCES}

1. Allison J.E. and Jones J.W, Butterworth-Heinemann, 1993, "Fundamentals of Metals Matrix Composites".

2. Budiansky B, 1965, "On the elastic moduli of some heterogeneous materials", J. Mech. Phys. Solids, Vol.13, p223.

3. Murali T. P, Surappa M. K and Rohatgi P. K, 1982, "Preparation and properties of Al-alloy coconut shell char particulate composites", Met. Trans., Vol.13B, p485.

4. Surappa M. K and Rohatgi P. K, 1981, "Preparation and properties of cast aluminiumceramic particulate composites", J. Mat. Sci. Vol.16, p983.

5. Banerji A, Surappa M. K and Rohatgi P. K., 1983, "Cast aluminum alloys containing dispersions of zircon particles", Met. Trans. Vol.14 B, p273.

6. Crowe C.R, Gray R.I and Hassan D.F, July 1985, "Microstructure controlled fracture toughness of SiC/Al metal matrix composites", Proc, 5th Int. Conf. Comp. Mat. SanDiego, p843.

7. Rohatgi P. K, Pai B. C and Panda S. C, 1979, "Preparation of cast aluminum-silica particulate composites", J. Mat. Sci., Vol.14, p2277.

8. Hasan Z, 2008, "Studies on Strength, Fracture, Fatigue and Wear Behavior of Al-SiC Particulate Composites", Ph.D. Thesis, IIT Delhi India.

9. Veerresh G.B Kumar, Rao C.S.P, and Selvaraj N, 2011, "Mechanical and Tribological Behaviour of Particulate Reinforced Aluminium Metal Matrix Composites- a review", JMMCE. Vol. 10, No. 01, p59.

10. Manoj S, Lakhvir S. and Vikas C, 2009, "Study of Wear Properties of Al-SiC Composites", JMMCE, Vol. 8, No. 10, p813. 